Dr. J. W. D. Bull for permission to quote from the radiologist's reports, and to Dr. Elizabeth Warrington for details of the psychometric assessments. We would also like to thank Dr. J. W. D. Bull, Dr. P. C. Gautier-Smith, and Dr. Elizabeth Warrington for helpful discussions.

\section{References}

Adams, R. D., Fisher, C. M., Hakim, S., Ojemann, R. G., and Sweet, W. H. (1965). New England Fournal of Medicine, 273, 117.

Bannister, R. (1970). Proceedings of the Royal Society of Medicine, 63, 921 Bannister, R., Gilford, E., and Kocen, R. (1967). Lancet, 2, 1014.

Bull, J. (1969). Brain, 92, 535 .

Gosling, R. H. (1955). Fournal of Neurology, Neurosurgery and Psychiatry, $18,129$.

Hunter, R., Blackwood, W., and Bull, J. (1968). British Medical fournal, 3, 9.
Kelly, R. (1951). Brain, 74, 23.

Kibler, R. F., Couch, R. S. C., and Crompton, M. R. (1961). Brain, 84, 45. Kiloh, L. G.' (1961). Acta Psychiatrica Scandinavica, 37, 336.

Logue, V., Durward, M., Pratt, R. T. C., Piercy, M., and Nixon, W. L. B. (1968). British fournal of Psychiatry, 114, 137.

Nevin, S., McMenemey, W. H., Behrman, S., and Jones, D. P. (1960) Brain, 83, 519. Olivarius, B. de F., and Roder, E. (1970). Acta Psychiatrica Scandinavica,

Riddoch, G. (1936). Brain, 59, 225.

Robinson, K. C., Kallberg, M. H., and Crowley, M. F. (1954). British Medical fournal, 2, 1203.

Sachs, S. (1950). Fournal of Mental Science, 96, 998.

Selecki, B. R. (1965). Medical fournal of Australia, 1, 383.

Strachan, R. W., and Henderson, J. G. (1965). Quarterly fournal of Medicine, 34, 303.

Tiberin, P., Goldberg, G. M., and Schwartz, A. (1958). Neurology (Minneapolis), 8, 51 . White, J. C., and Cobb, S. (1955). Archives of Neurology and Psychiatry,
74, 383.

\title{
Acute Asymmetrical Neuritis Associated with Rapid Ultrafiltration Dialysis
}

\author{
ALAIN MEYRIER, MICHEL FARDEAU， GABRIEL RICHET
}

British Medical fournal, 1972, 2, 252-254

\begin{abstract}
Summary
Three patients with chronic renal failure treated by haemodialysis developed acute asymmetrical sensory and motor neuropathies when ultrafiltration was induced to treat oedema. The neuropathies were characteristic of acute mononeuritis multiplex rather than uraemic polyneuritis, and we give our reasons for believing that they were not caused by toxic uraemic metabolites but by an ischaemic process due to vasoconstriction resulting from ultrafiltration.
\end{abstract}

\section{Introduction}

Peripheral neuropathies in patients undergoing intermittent haemodialysis were first noted in 1961 and later described in detail (Hegstrom et al., 1962). They usually lead to bilateral and symmetrical defects due to distal non-inflammatory destruction of myelinated fibres, and often affect debilitated patients in whom dialysis was started late. Infrequent dialyses together with restricted protein intake may also cause rapid nerve damage which regresses when the number and duration of dialyses are increased (Lange and Lonergan, 1969), and a progressive neuropathy during maintenance haemodialysis is usually considered a sign of "inadequate dialysis" (Jebsen et al., 1967). The pathophysiology of the condition is poorly understood, and a neurotoxic dialysable metabolite (Tenckhoff et al., 1967; Giovannetti et al., 1969), a lack of some neurotrophic substance (Callaghan, 1966; Tyler, 1968), and an impairment of carbohydrate tolerance (Asbury et al., 1963) have been suggested as causes.

We have seen a rapidly progressive neuropathy in three patients undergoing maintenance haemodialysis in which

\section{Nephrology Unit, Hôpital Tenon, Paris 20ème \\ ALAIN MEYRIER, M.D., Consultant}

GABRIEL RICHET, M.D., Professor of Medicine

Department of Electron Microscopy, H6́pital de la Salpêtrière, Paris 13eme

MICHEL FARDEAU, M.D., Head of Research several of the features were those of a mononeuritis multiplex rather than of the polyneuritis usually seen in these cases. The rapid onset, distribution, asymmetry, and the triggering role of ultrafiltration suggested separate lesions of ischaemic origin affecting several distinct nerve stems or roots. These are characteristic of mononeuritis multiplex. In one case electron microscopy of nerve and muscle tissue showed vascular lesions which supported the diagnosis.

\section{Case 1}

A man aged 31 had had chronic renal disease for more than 20 years. In May 1968 his blood urea nitrogen was $210 \mathrm{mg} / 100 \mathrm{ml}$ and his blood pressure $180 / 110 \mathrm{~mm} \mathrm{Hg}$. There were no neurological abnormalities, except that the nerve conduction velocity in both peroneal nerves was $34 \mathrm{~m} / \mathrm{sec}$ (normal, $40 \pm 5 \mathrm{~m} / \mathrm{sec}$ ). There was no impairment in other peripheral nerves.

Like the other two patients, this patient was dialysed twice weekly for eight hours via an arteriovenous fistula between the left radial artery and the nearest vein, using Travenol coil UF 145. Ultrafiltration was applied during the third dialysis on 29 May, and two hours after it began the patient suddenly complained of right otalgia which was fcllowed by a right-sided Bell's palsy. There was a loss of tendon reflexes in the right upper and both lower limbs. The plantar responses were flexor. Systolic blood pressure had fallen to $60 \mathrm{~mm} \mathrm{Hg}$ on ultrafiltration but rose with saline infusion. Three hours after the end of dialysis the right facial palsy subsided and the blood pressure was $150 / 90 \mathrm{~mm} \mathrm{Hg}$ when the patient was lying down and $90 / 70 \mathrm{~mm} \mathrm{Hg}$ when upright.

Before the fourth dialysis on 1 June there was loss of flexion and lateral movements of the third, fourth, and fifth fingers of the left-hand; loss of all tendon reflexes except those of the left biceps and triceps; sensory loss in the area of the median nerve; and a partial impairment of the right sixth cranial nerve. One hour after beginning haemodialysis there were observed successively a reappearance of the right Bell's palsy (after otalgia), sensory loss in the right ulnar nerve, and complete paralysis of the right sixth cranial nerve with diplopia. Three hours later there were distal paralysis and anaesthesia of both legs and sensory loss in the whole right hand. After the dialysis ended all the neurological signs subsided within a few hours except those which were present before dialysis and the right facial paralysis, which persisted. During dialysis the serum phosphorylated thiamine was $8 \mu \mathrm{g} / 100$ $\mathrm{ml}$ (normal, $3.5 \mu \mathrm{g} / 100 \mathrm{ml}$ ), and the next day the serum pyruvate was $0.62 \mathrm{mg} / 100 \mathrm{ml}$ (normal, $0.5 \pm 0.1 \mathrm{mg} / 100 \mathrm{ml}$ ). 
On 17 June the patient was transferred to another hospital for a renal transplantation. After several rejection episodes renal function was stabilized with a glomerular filtration rate of 45 $\mathrm{ml} / \mathrm{min}$. The paralysis and sensory loss in both legs and in the left upper limb and the right Bell's palsy persisted until the end of 1968, when they began to regress. By the end of 1969 the neurological signs had completely disappeared.

\section{Case 2}

This 35-year-old man had chronic renal disease due to renal hypoplasia. Overt renal failure had begun in 1958. In November 1968 his blood urea nitrogen was $330 \mathrm{mg} / 100 \mathrm{ml}$ and serum creatinine $8.5 \mathrm{mg} / 100 \mathrm{ml}$. A uraemic pericarditis supervened. Nerve conduction velocities, tested three weeks before starting dialysis, were: right peroneal nerve $28 \mathrm{~m} / \mathrm{sec}$, left peroneal nerve $39 \mathrm{~m} / \mathrm{sec}$, right ulnar nerve $45 \mathrm{~m} / \mathrm{sec}$, and left ulnar nerve $60 \mathrm{~m} / \mathrm{sec}$

Haemodialysis was started on 23 November 1968. There was gross overhydration, and the weight loss from each dialysis was 2-3 kg. Within three weeks $15 \mathrm{~kg}$ had been removed (Fig. 1). At this time the patient began to complain of burning feet and of

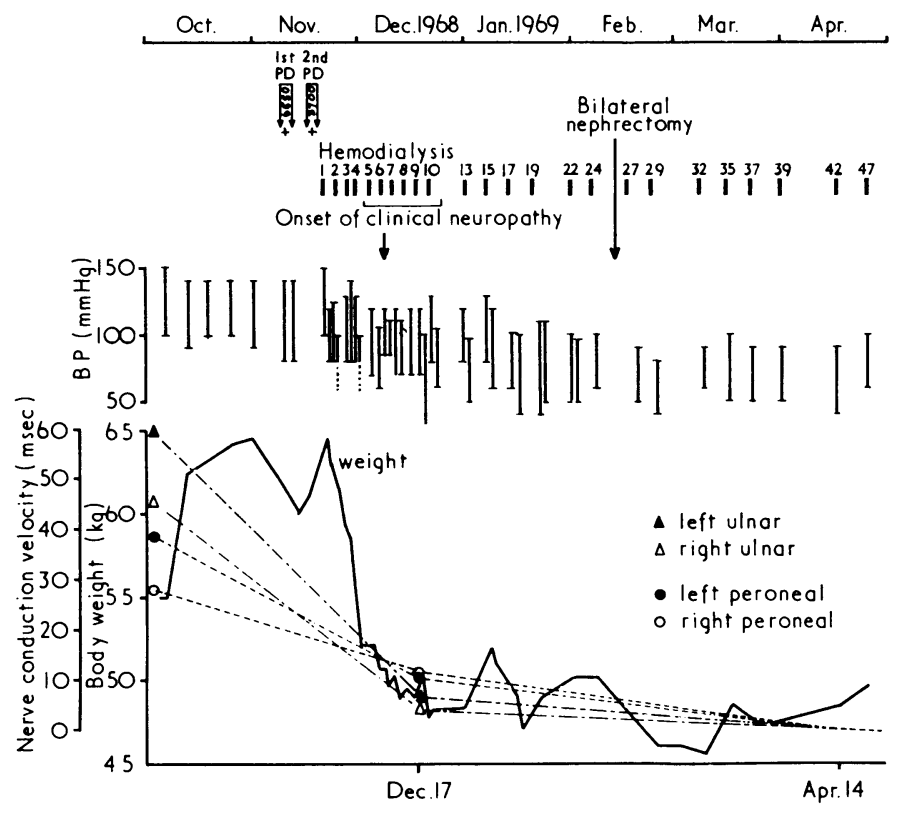

FIG. 1-Chart of clinical measurements related to treatment and onset of neuropathy in Case 2.

paraesthesiae of the left hand. There was a loss of tendon reflexes in both lower limbs and impairment of deep sensation in the feet. On 17 December nerve conduction velocities were decreased, as follows: right peroneal $10 \mathrm{~m} / \mathrm{sec}$, left peroneal $10 \mathrm{~m} / \mathrm{sec}$, right ulnar nerve $5.5 \mathrm{~m} / \mathrm{sec}$, and left ulnar nerve $8 \mathrm{~m} / \mathrm{sec}$. Serum pyruvate was $0.24 \mathrm{mg} / 100 \mathrm{ml}$. From then on the peripheral neuropathy developed rapidly.

After bilateral nephrectomy on 10 February 1969 the neuropathy continued to develop, and a complete symmetrical paralysis of both legs with crippling muscular wasting and sensory loss up to the knees ensued. Then paralysis of the left hand distal to the arteriovenous fistula suddenly appeared. It was restricted to the area supplied by the median nerve, with loss of thumb abduction and muscular atrophy. There were no signs of damage to the central nervous system or to the cranial nerves. There was no further extension of the neuropathy. Motility was restored in the left hand in eight months, and by March 1970 the patient was able to walk without a stick.

\section{Case 3}

This 22-year-old man had had chronic glomerulonephritis since the age of 6. Renal failure and hypertension appeared in 1963.
Neurological examination and nerve conduction velocity measurements before the first dialysis on 7 August 1969 were normal. The average predialysis body weight was $73 \mathrm{~kg}$. From 26 December drastic ultrafiltration was applied during each dialysis in an attempt to reduce the persistently high diastolic blood pressure. At this time (five months after the start of dialysis) the neurological state was still normal. Within four weeks the patient lost $11 \mathrm{~kg}$, and with each dialysis there were sharp blood pressure fluctuations, severe muscular cramps, and distal paraesthesiae. After a brief improvement the blood pressure rapidly rose to previous levels (Fig. 2). But after the dehydration a bilateral but strikingly asymmetrical neuropathy of the lower limbs developed.

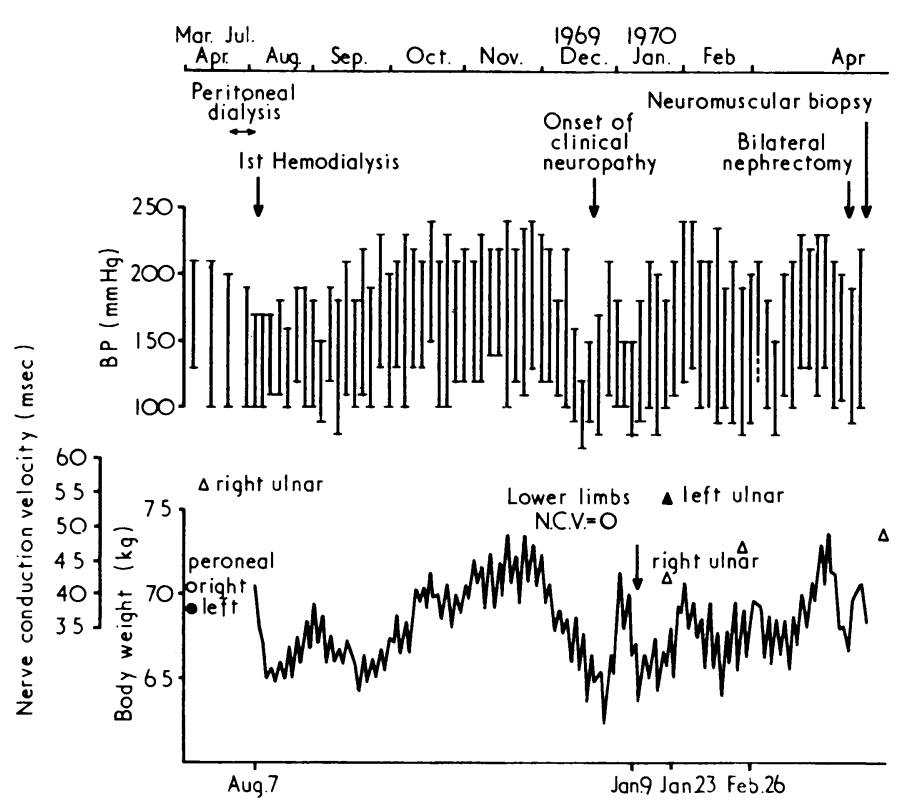

FIG. 2-Chart of clinical measurements related to treatment and onset of neuropathy in Case 3.

Paralysis was most pronounced in the left peroneal area, with only slight weakness in the right leg. All tendon reflexes in the lower limbs were lost. Nerve conduction velocities fell abruptly to unmeasurable levels in both lower limbs.

In the light of Cases 1 and 2 it was thought that rehydration might reverse the trend, and a gain in weight of $7 \mathrm{~kg}$ over a period of one month was allowed. After this there was no further development of the neuropathy, muscle strength improved, and the knee jerks returned. Nerve conduction velocities remained unchanged. The blood pressure fell after bilateral nephrectomy on 8 April 1970, and the neuropathy continued to improve slowly.

A biopsy of the left peroneus brevis nerve on 20 April showed under light microscopy a severe rarefaction of the myelinated fibres and a moderate increase in number of the Schwann cell nuclei. With electron micropsy many unmyelinated axons were visible besides the rare intact myelinated fibres. Some axons were wrapped in an abnormally thin myelin sheath. In several places the Schwann cytoplasm looked slightly turgid, its clear appearance contrasting with the axoplasmic electron density. Many Schwann processes contained myelin debris, rarely forming an early whorl. Most of the capillary vessels were remarkable for the intense swelling of the endothelial cells.

Biopsy of the peroneal muscle under light microscopy showed typical fascicular atrophy of the fibres. Histochemically the atrophy preferentially involved type II fibres rich in myofibrillar adenosine triphosphatase, but many atrophic fibres of this group were as rich in oxydative enzymes as the normal type I fibre. Electron microscopy showed many foci of myofibrillar disintegration with streaming of the $\mathrm{Z}$ band, often located in the central part of the fibre. These foci were also remarkable for the presence of swollen mitochondria, dilated reticulum, and numerous dense bodies. As in the nerve biopsy, the capillary walls were often swollen with numerous pinocytic vesicles at their periphery. 


\section{Discussion}

The onset of the neuropathies in these three cases coincided with the application of ultrafiltration to treat extracellular overhydration. Each dialysis with ultrafiltration in Cases 1 and 2 was marked by sharp drops in blood pressure and peripheral vasoconstriction, and the neuropathy developed shortly after and progressed rapidly. The role of ultrafiltration seems also well established in Case 3. The neurological signs appeared after five months of well-tolerated dialyses and when a large weight loss had been therapeutically induced. Moreover, in the light of Cases 1 and 2 it was decided to induce a rapid increase of body weight by saline infusion during dialysis. Only then was a definite improvement in the neuropathy noted.

The three cases share other notable features. The patients, though all suffering from protracted chronic renal insufficiency, had minimal (in two) or no (in one) neurological defects t efore starting on dialysis. In none was any systemic disease, si ch as diabetes, amyloidosis, or hereditary nephropathy, detect $t \mathrm{~d}$ or any other illness liable to cause segmental neural lesions. The onset of the neuropathy was rapid, the interval between starting ultrafiltration dialysis and the finding of overt neurological defects being one, three, and four weeks respectively. The distribution was distinctly asymmetrical and differed from that usually found in polyneuritis, which affects numerous distal nerves whose areas overlap and has glove-and-stocking paraesthesiae. In these three cases the clinical features suggested separate lesions of several distinct nerve stems or roots, and this is characteristic of mononeuritis multiplex.

\section{PHYSIOPATHOLOGY}

It is improbable that these cases of mononeuritis were caused by some uraemic dialysable metabolite since they developed after dialysis was started. Dialysis might have shifted an unstable equilibrium by subtracting some essential neurotrophic element. For example, several essential amino-acids are lost during each dialysis (Giordano et al., 1968) and this could be detrimental to patients debilitated by protein restriction and by vomiting. This was indeed the case in our patients, but it should presumably give rise to generalized not multifocal disorders.

The clinical features, which closely resembled those of polyarteritis nodosa, are strongly suggestive of an ischaemic process. The acute onset of a neuropathy shortly after the start of maintenance haemodialysis has been described by several authors (Konotey-Ahulu et al., 1965; Tenckhoff et al., 1965; Dinopoli et al., 1966; New England Fournal of Medicine, 1967; Schupack et al., 1967; Jennekens et al., 1969), but unfortunately they did not indicate the rate of ultrafiltration during the initial dialyses. The case described by Popovtzer et al. (1969) is highly suggestive of nerve lesions induced by an ischaemic process. After a month of ultrafiltration a severe polyneuropathy developed. Bilateral nephrectomy produced a sharp drop in blood pressure which necessitated compensation by saline infusions. From then on the nerve lesions rapidly improved. The authors suggested that they were due to severe ischaemia caused by renin vasoconstriction of the vasa nervorum. A strikingly similar case was reported by Romagnoni and d'Amico (1970).
We believe that a mononeuritis multiplex was caused in our three patients by a similar combination of events. The vasoconstriction was induced by ultrafiltration, producing a massive release of catecholamines and renin. Previous nerve damage by chronic uraemia (Dayan et al., 1970; Dinn and Crane, 1970) and vascular segmental changes from hyperparathyroidism (Parfitt, 1969) could have predisposed towards a neuropathy. The fact that in the first patient some lesions regressed rapidly while others did not heal for several months suggests the possibility of ischaemic spasms inducing segmental necrosis of nerve fibres, and may be compared with a Bell's palsy regressing after decompressive surgery (Langworth and Taverner, 1963). The ischaemic nature of these neuropathies could be proved only by careful dissection of all roots and nerve trunks. Nevertheless, the electron microscope examination showed swelling of the endothelial cells of the capillary walls, a finding never reported in cases of uraemic polyneuropathy.

These cases show the need for prudent and gradual ultrafiltration, particularly during the first dialyses. This is especially true when therapeutic dehydration induces distal paraesthesiae, muscular cramps, and temporary distal paresis. These symptoms occurring in patients with a malignant hypertension which resists sodium and water depletion should therefore be considered as an indication for early bilateral nephrectomy rather than for drastic extracellular fluid reduction.

We gratefully acknowledge the help of $\mathrm{Mr}$. Paul Houlbreque in preparing the bibliography and of Mrs. Jennifer Hale and Mrs. Nitza Pauleau for reviewing the text.

\section{References}

Asbury, A. K., Victor, M., and Adams, R. D. (1963). Archives of Neurology, 8,413 .

Callaghan, N. (1966). Irish fournal of Medical Science, 6th series, p. 325.

Dayan, A. D., Gardner-Thorpe, C., Down, P. F., and Gleadle, R. I. (1970) Neurology (Minneapolis), $20,649$.

Dinn, J. J., and Crane, D. L. (1970). Fournal of Neurology, Neurosurgery and Psychiatry, 33, 605 .

Dinopoli, R. P., Johnson, W. J., and Lambert, E. H. (1966). Proceedings of the Staff Meetings of the Mayo Clinic, 41, 809.

Giordano, C., et al. (1968). Nutrition and Renal Disease, ed. G. M. Berlyne, p. 23. Edinburgh, Livingstone.

Giovannetti, S. et al. (1969). Clinical Science, 36, 445

Hegstrom, R. M., Murray, J. S., Pendras, J. P., Burnell, J. M., and Scribner B. H. (1962). Transactions. American Society for Artificial Internal Organs, 8, 266.

Jebsen, R. H., Tenckhoff, H. A., and Honet, J. C. (1967). New England fournal of Medicine, 277, 327.

Jennekens, F. G., Van der Most van Spijk, D., and Dorhout Mees, E. J. (1969). Proceedings of the European Dialysis and Transplant Association, 6, 191 .

Konotey-Ahulu, F. I. D., et al. (1965). British Medical fournal, 2, 1212

Lange, K., and Lonergan, E. T. (1969). Abstracts of the American Society of Nephrology, Third Annual Meeting, p. 38.

of Nephrology, Third Annual Meeting, p. 38.
Langworth, G., and Taverner, J. (1963). Brain, 86, 465.

Langworth, G., and Taverner, J. (1963). Brain, 86,
New England fournal of Medicine, 1967, 277, 371 .

New England Fournal of Medicine, 1967, 277, 371.
Parfitt, A. M. (1969). Archives of Internal Medicine, 124, 54

Parfitt, A. M. (1969). Archives of Internal Medicine, 124, 544. (1969). New England fournal of Medicine, 281, 949.

Romagnoni, M., and d'Amico, G. (1970). New England fournal of Medicine, 282, 1271 .

Schupack, E., Sullivan, J. F., and Lee, D. Y. (1967). Annals of Internal Medicine, 67, 708 .

Tenckhoff, H. A., Boen, F. S., Jebsen, R. H., and Spiegler, J. H. (1965) fournal of the American Medical Association, 192, 1121 .

Tenckhoff, H., Jebsen, R. H., and Honet, J. C. (1967). Transactions. American Society for Artificial Internal Organs, 13, 58.

Tyler, H. R. (1968). American fournal of Medicine, 44, 734. 